\title{
Measurement and Study on Winter Indoor Thermal Environment of Civilian Dwelling in South Rural Areas of Shaanxi Province
}

\author{
Pengchen Liu',b, Guochen Sang ${ }^{3, c}$, Qin Zhao ${ }^{3, d}$, Yiyun Zhu', a \\ ${ }^{1}$ NO.5 Jinhua South Road,Xi'an, China \\ ${ }^{2}$ NO.5 Jinhua South Road,Xi'an, China \\ ${ }^{3}$ NO.5 Jinhua South Road,Xi'an, China \\ azyyun@xaut.edu.cn, bliupengchen2013@163.com, 's sanggc2002@126.com, \\ dzhaogin6688@xaut.edu.cn
}

Keywords: the south region of Shaanxi; civilian dwelling ;measurement of thermal environment;design strategy

Abstract. With the civilian dwelling in the rural areas of Hanzhong in the south of Shaanxi province as research subject, through the questionnaire and on-site measurement, the paper explores the situation of winter indoor thermal environment of local civilian dwelling as well as the measures for improvement. Based on the measurement data, combing the architectural features, the paper analyzed the influences on indoor thermal environment caused by the factors like building construction and indoor space arrangement. The results show that due to the unreasonable indoor space arrangement, the poor thermal performances of building envelope and the low efficiency of solar energy utilization, the winter indoor thermal environment has poor quality, therefore, leading to lower room temperature and higher relative humidity. With regard to the climate situations and building properties of civilian dwelling in the areas of the south of Shaanxi province, the paper proposes the suitable design strategy for the improvement of winter indoor thermal environment in these areas.

\section{Introduction}

The south region of Shaanxi refers to the areas in the south of Shaanxi province, the region extends to the Mt. Qinling in the north and Mt. Bashan in the south with subtropical continental monsoon climate, and it's not very hot in summer and not very cold in winter in these areas. The traditional architecture form of the civilian dwelling in this region is earth construction, along with the economy development in recent years in these areas, the civilian dwelling with earth construction is gradually transforming into brick and concrete construction. Presently, the construction of brick and concrete civilian dwelling mostly follows the self-built pattern, owing to the lack of scientific design, the thermal performances of construction are not ideal, and can't meet the demands of residents for indoor thermal comfort. The paper carries out the questionnaire on the present situations of civilian dwelling and the residents' subjective feelings of thermal and humidity in Hanzhong region, selects the typical brick and concrete civilian dwelling as research target, takes on-site measurement and analysis of the indoor and outdoor thermal environment parameters. From the study, the paper will point out the problems existed in the present brick and concrete civilian dwellings, propose suitable and energy saving design strategy, offer some references for the design of civilian dwelling in the south of Shaanxi province and the same regions.

\section{General Situation of Civilian Dwelling.}

With on-site investigation for the villages in the rural areas of Hanzhong city in the south of Shaanxi province, it's found that the civilian dwellings in these areas can be classified into three types according to the construction periods: The traditional earth civilian dwellings built before the year of 1980, the early brick and concrete houses built between 1980-2000, and the new type brick and concrete houses built since 2000 till now. At present, there are less traditional earth houses in 
the villages and most of the dwellings are early brick and concrete houses and new type brick and concrete houses. All kinds of civilian dwellings are shown in Fig 1.

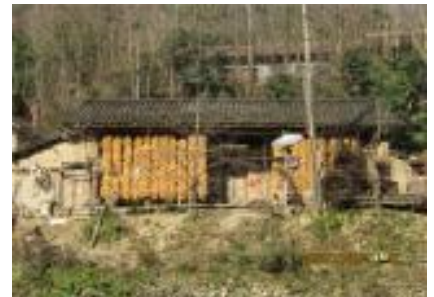

(a) traditional earth civilian dwelling

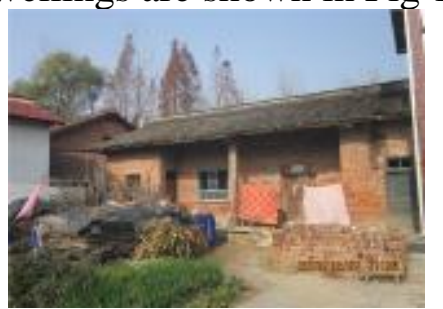

(b) early brick and concrete civilian dwelling

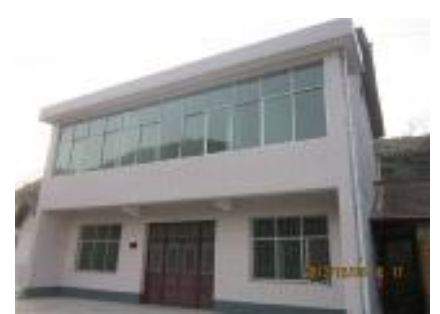

(c) new type brick and concrete dwelling Fig.1 All kinds of civilian dwellings in the rural areas in the south of Shaanxi Province

The present civilian dwellings mostly are built toward south and with the back against north, the indoor space arrangements are simple with larger building construction coefficient, the insulation treatment was not designed basically, but the different civilian dwellings have different construction features. The traditional earth civilian dwellings mainly adopt single-layer slope roof, the exterior windows are wood with single-layer glass, the window-wall ratio is smaller. In comparison with the traditional earth civilian dwelling, the early brick and concrete civilian dwellings have no special changes except for the building materials changing from adobe into solid clay brick. The new type of brick and concrete dwellings are mainly two-floor buildings, comparing with the early brick and concrete dwellings, the new types have larger window-wall ratio, moreover, the enclosed balcony is built.

\section{Residents' Subjective Feelings of Thermal and Humidity.}

The residents' subjective feelings include thermal feeling and humidity feeling; the data comes directly from questionnaires. There are 45 households involved in investigation and 110 persons are questioned, the average age is 42.5 , the ratio of men to women is $1: 2.5$. the investigation data statistics are shown in Table 1.

Tab. 1 Investigation statistics of the resident's thermal and humidity feelings

\begin{tabular}{ccc}
\hline \multirow{2}{*}{$\begin{array}{l}\text { Investigation } \\
\text { Contents }\end{array}$} & \multicolumn{2}{l}{ Results Statistic } \\
\hline Day temperature feeling of & Cold & Not cold \\
\cline { 2 - 3 } the room in winter & $53 \%$ & $47 \%$ \\
\hline $\begin{array}{c}\text { Night temperature feeling } \\
\text { of } \\
\text { the room in winter }\end{array}$ & Cold & Not cold \\
\cline { 2 - 3 } $\begin{array}{c}\text { Humidity feeling of the } \\
\text { room in winter }\end{array}$ & Humid & $\begin{array}{c}\text { Not } \\
\text { humid }\end{array}$ \\
\cline { 2 - 3 } & $68 \%$ & $32 \%$
\end{tabular}

From the results of investigation, it can be obtained that most of the residents subjectively feel colder in the room in winter, particularly at night. In comparison with day time, the number of people who feel colder at night increase by $14 \%$. The humidity in the room is higher, nearly $70 \%$ residents feel humid in the room, that it's cold and humid in winter is the typical feature of indoor thermal environment for local residents.

The questionnaire reflects subjectively the thermal and humidity feelings of local residents, it is certainly representative. In order to know the indoor thermal environment situations in local civilian dwellings and analyze its influential factors, it's very necessary to make on-site measurement of thermal environment for local civilian dwelling.

\section{Measurement and Analysis of Indoor and Outdoor Thermal Environment.}

\subsection{Measurement scheme}

In the research, a local and typical new type brick and concrete civilian dwelling is chosen as measurement target. The dwelling has been built toward south and with the back against north, it 
has two floors, the enclosed balcony is built on the second floor, the roof is built with a slope, the tiles are directly placed on the wood rafter, no insulation layers are installed. The exterior wall is built with $240 \mathrm{~mm}$ thick solid clay brick, plastering is given inside and outside of the wall, and there are no additional insulation layers to be installed. The exterior doors are wood; the exterior windows are casement single-layer glass wood windows. The layout and distribution of measure points on the first and the second floors are shown in Fig 2.

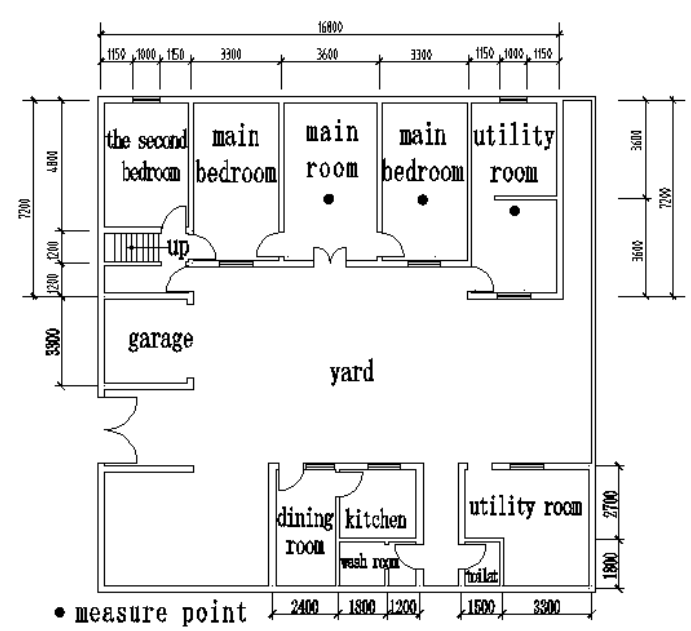

(a) the first floor

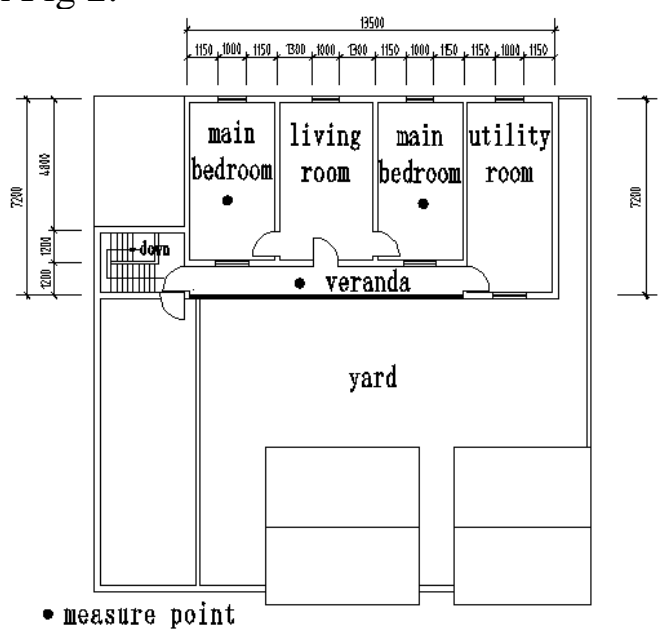

(b) the second floor

Fig. 2 The layout and distributions of measure points of new type brick and concrete civilian dwelling

The contents of measurement include the temperature and humidity of indoor and outdoor air, the intensity of solar radiation as well. TR-72U Thermohygraphs are adopted to record the temperature and humidity of air, the accuracy of measurement is $\pm 0.2^{\circ} \mathrm{C}$, the data-collection interval is $1 \mathrm{~h}$, the distribution of indoor measurement points is shown in Fig.2, the outdoor measurement points are placed in the shade, the solar radiation is measured with TBD-1 shading ring, working together with TBQ-2 pyranometer, the measuring range of radiation meter is $0 \sim 2000 \mathrm{~W} / \mathrm{m}^{2}$, the sensitivity coefficient is $8.789 \mu \mathrm{V} /\left(\mathrm{W} \cdot \mathrm{m}^{2}\right)$, measure points are placed in outdoor open areas, there are no any shelters around.

3.2 Measurement results and analysis

The project team measured the indoor and outdoor thermal environment from 15 to 17 of January 2014. Measurement results of temperature for the outdoor and main rooms of the civilian dwelling are shown in Fig 3 and Fig 4 respectively, the measurement results of relative humidity are shown in Fig 5, the measurement results of solar radiation intensity are shown in Fig 6.

\subsubsection{Indoor and outdoor air temperature}

The outdoor average air temperature is $4.0^{\circ} \mathrm{C}$ during measurement, the average value of temperature daily range is $7.5^{\circ} \mathrm{C}$, the average temperatures in hall, east main bedroom and utility room on the first floor are $10.9^{\circ} \mathrm{C}, 8.6^{\circ} \mathrm{C}, 6.5^{\circ} \mathrm{C}$ respectively, the average values of temperature daily range are $4.5^{\circ} \mathrm{C}, 1.9^{\circ} \mathrm{C}, 3.3^{\circ} \mathrm{C}$ respectively.

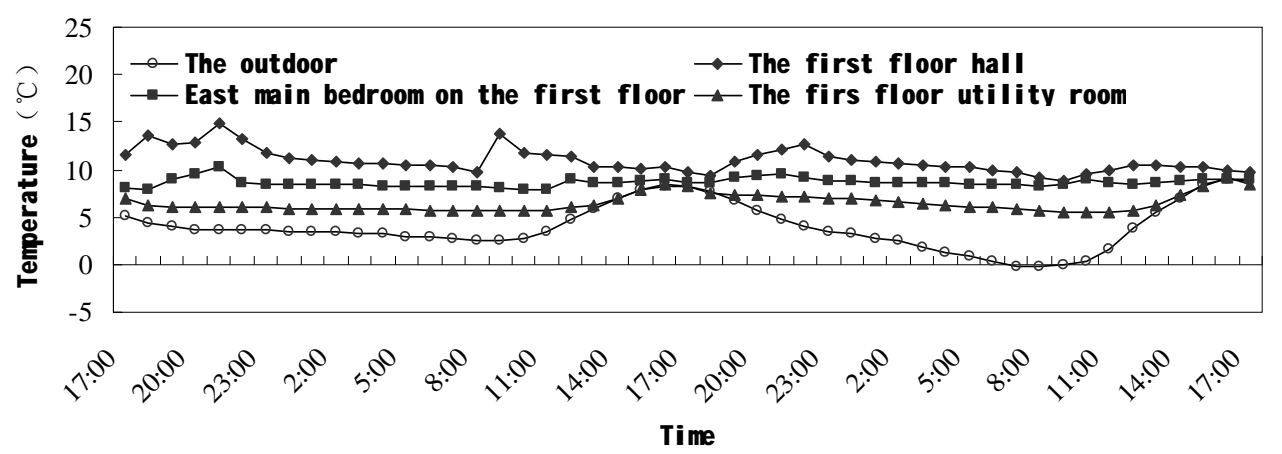

Fig. 3 The air temperature of the outdoor and main rooms of the civilian dwelling on the first floor 


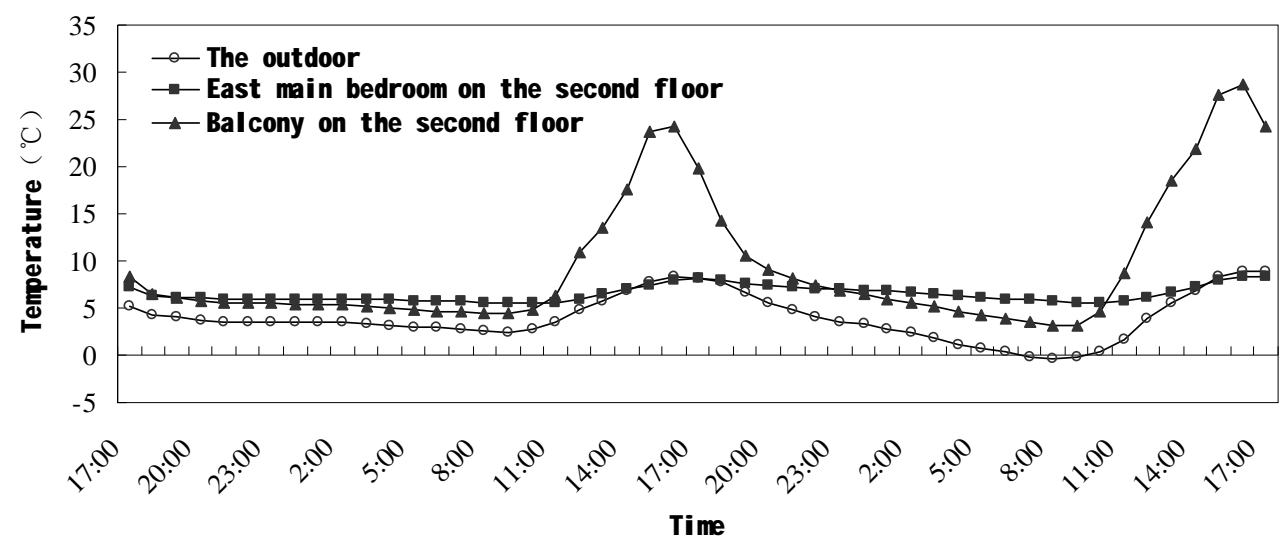

Fig.4 The air temperature of the outdoor and main rooms of the civilian dwelling on the second floor

It can be found from Fig 3 that the indoor temperature of the rooms on the first floor is lower, and can't meet the thermal environment index for the rural dwelling[1,2]. The constructions of the exterior wall, roof and exterior window of this dwelling are not good enough, besides, the whole heat-transfer coefficient of envelope is larger, the thermal performance is poorer, all of these lead to the temperature lower in the rooms. Comparing with the east main bedroom and utility room, the hall on the first floor has the highest average temperature, the temperatures are $2.3^{\circ} \mathrm{C}$ and $4.4^{\circ} \mathrm{C}$ higher respectively, the main reason is that the oven is placed inside of the hall for heating both in the morning and evening. In addition, the stability of temperature in each of the room is different. The measurement results in Fig 3 show that the temperature fluctuation in the hall is at maximum, reaching to $6.1^{\circ} \mathrm{C}$, it's higher obviously than the other rooms, the reason lies in intermittent heating and higher opening frequency of exterior door. The temperature stability in east main bedroom on the first floor is the best, its magnitude of temperature fluctuation is only $1.9^{\circ} \mathrm{C}$, this is because the east main bedroom locates in the middle of whole dwelling, it has less areas exposed to the outside of the room, and outdoor thermal environment has less effect on it, therefore, the east main bedroom has smaller temperature fluctuation in comparison with the other rooms. Accordingly, it can be deduced that a reasonable room space arrangements of the dwelling can maintain a good indoor thermal environment[3].

The average temperature in east main bedroom on the second floor is $6.5^{\circ} \mathrm{C}$, the average temperature daily range is $2.7^{\circ} \mathrm{C}$, since its position is at the top floor of the dwelling, comparing with east bedroom on the first floor, average temperature is lower. The average temperature in balcony on the second floor is $9.5^{\circ} \mathrm{C}$, average temperature daily range is $22.7^{\circ} \mathrm{C}$, the temperature fluctuation varies greatly. The main reason is that the areas of the exterior window at the balcony are larger; the windows are single-layer glass and aluminum alloy, the windows have a good effect of passive heat-collecting in daytime[4], meanwhile, the exterior windows have bigger heat transfer coefficient, the indoor partition walls are solid clay brick walls with lower heat storage coefficient, so heat storage ability is limited, and the heat loss at night is heavier, leading to lower temperature at night accordingly.

3.2.2 Indoor and outdoor relative humidity

It can be found From Fig 5 that the relative humidity fluctuation generally is opposite to the air temperature fluctuation, that is to say, the higher the air temperature is, the lower the relative humidity. The outdoor air has higher relative humidity, the average value is $72.3 \%$, and the variation range is $59.2 \% \sim 89.0 \%$.

The average relative humidity in east main bedrooms on the first floor and the second floor is $69.9 \%$, and $56.4 \%$ repectively, the wave amplitude is $17.0 \%$, and $9.5 \%$ respectively, this has approached the upper limit of human body's humidity comfort [5,6]. That the indoor humidity is higher and with lower temperature will make human body feel subjectively cold and humid. The average values of relative humidity of the hall on the first floor and the balcony on the second floor are $49.7 \%$ and $51.1 \%$, in which the relative humidity fluctuation of the hall on the first floor is less, nevertheless, the relative humidity fluctuation of balcony on the second floor is drastic, wave amplitude reaches to $44.4 \%$. 


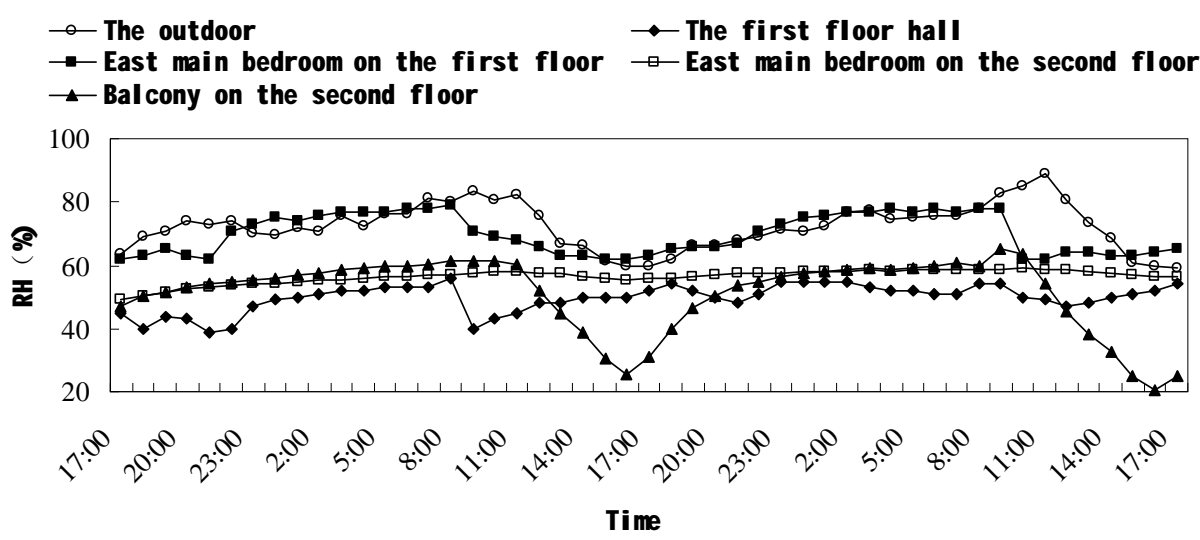

Fig. 5 The relative humidity of the outdoor and main rooms of civilian dwelling

\subsubsection{Intensity of solar radiation}

The measurement contents for intensity of solar radiation include horizontal general radiation and sky scattering radiation, the measurement results are shown in Fig 6. On measurement day the sunshine continues 8 10h, the available sunshine records on measurement day is from 9:00-18:00, the peak value of general radiation is $547 \mathrm{~W} / \mathrm{m} 2$, it appears around 13:00 in the afternoon, the average value of general radiation is $295 \mathrm{~W} / \mathrm{m} 2$. The radiation intensity of direct sunshine accounts for $71.5 \%$ of total intensity of radiation. Though the solar radiation intensity in winter in these areas is lower comparing with the areas in winter in Xizang and Ningxia where the solar energy resources are rich[7,8,9], it still can be utilized, the heating problems will be resolved partially if the solar energy is used properly[10,11,12].

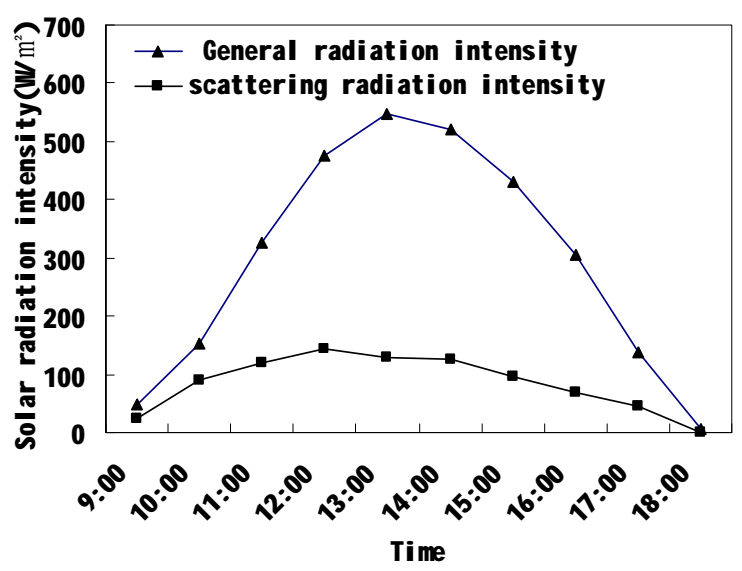

Fig.6 Outdoor solar radiation intensity

\section{Conclusions and Suggestions.}

By carrying out the questionnaire for rural areas in the south of Shaaxi province as well as the measurement on indoor and outdoor thermal environment of the typical civilian dwelling, we can find that the indoor thermal environment of civilian dwelling in winter in these areas is poor, it's cold and humid inside the rooms. Though The new type of brick and concrete dwellings built by themselves have certain progress in the functions of use, its construction thermal performances are still less, the house space arrangement is not reasonable and has low utilization of solar energy, all of these are unfavorable for the improvement of indoor thermal environment. With measurement and analysis, the following suggestions are proposed.

1) It can be considered that the civilian dwellings are built two households or multi-households together in lines, fully using public walls to reduce exterior exposed areas. The south-north and two-way layout of civilian dwellings should be adopted, the main rooms are arranged toward south, secondary rooms are arranged toward north.

2) Shale resources are very rich in Hanzhong region, the shale perforated bricks can be used as exterior wall materials, meanwhile, insulation layers are placed on the exterior wall and roof, the 
thermal performance of non-transparency envelope should be improved to reduce indoor heat loss in winter.

3) Exterior windows toward south should be properly enlarged so as to allow much solar radiation entering the room and increase indoor temperature. At the same time, double-layer glass plastic windows should be installed to improve the air tightness, reduce heat loss and cold wind inflow through the windows.

4) The enclosed balcony on the second floor of new type brick and concrete dwelling has a certain effect of solar heat-collecting, this indicates that passive heat-collecting design can be taken to increase the quality of indoor thermal environment. Furthermore, a sun room can be set up at the entrance of dwelling to prevent cold wind from flowing, forming a temperature buffer to adjust indoor temperature of the hall. Meanwhile, partition wall in the sun room should be built with heavy materials, and set up insulation curtain to reduce the heat loss at night.

\section{Acknowledgements}

This work was financially supported by the National Natural Science Foundation of China (No. 51378424),the Science and Technology Developing Project of Shaanxi Provincial (Project No. 2012K12-01-03) and the Key Social Development Program of Shaanxi Provincial (Program No. 2012K12-04-01).

\section{References}

[1] ASHRAE.ASHRAE Handbook of Fundamentals American Society of Heating Refrigeration and Air-Conditioning Engineers(Atlanta 2004).

[2] Yiyun Zhu, Jiaping Liu. Research on the Indoor Thermal Environment of Rural Architecture in Winter in Northwestern Areas. China Civil Engineering Journal.Vol.43(2010), p.400-403.

[3] Shaoqing Gou, Zhengrong Li, Qun Zhao, Vahid M. Nik, Jean-Louis Scartezzini. Climate responsive strategies of traditional dwellings located in an ancient village in hot summer and cold winter region of China. Building and Environment.Vol.86(2015), p.151-165.

[4] Alfredo Fernández-González. Analysis of the thermal performance and comfort conditions produced by five dierent passive solar heating strategies in the United States Midwest. Solar Energy.Vol.81(2007), p.581-593.

[5] Fanger P O. Thermal Comfort. Danish technical press(Copenhagen 1970).

[6] Jiaping Liu. Building Physicals(China Building Industry Press, Beijing 2009).

[7] Dengjia Wang, Yanfeng Liu, Yi Wang, Jiaping Liu. Measurement and Evaluation of Indoor Thermal Environment of Residential Buildings in Lhasa in Winter. Building Science.Vol.27(2011), p.20-24.

[8] Hejiang Sun, Muji Leng. Analysis on Building Energy Performance of Tibetan Traditional Dwelling in Cold Nural Area of Gannan. Energy and Buildings.Vol.96(2015), p.251-260.

[9] Dalong Liu, Jiaping Liu, Quan He, Liangliang Zhai. Investigation of Thermal Evironment for Yinchuan Traditional Dwelling Building in Winter. Journal of Xi' an University of Architecture \& Technology(Natural Science Edition).Vol.42(2010), p.83-86.

[10] Wenxue Zhao, zhuigang An, Jiaping Liu. Analysis of Indoor Thermal Environment Test of New Civil Housings in Guanzhong Area, Shaanxi Province in Winter. Building Science.Vol.29(2013), p.72-76.

[11] Bodach S, Lang W, Hamhaber J. Climate Responsive Building Design Strategies of Vernacular Architecture in Nepal. Energy and Buildings.Vol.81(2014), p.227-242.

[12] Rongrong $\mathrm{Hu}$, Wanpeng Li, Wenfang He, Jiaping Liu. Study on Winter Indoor Thermal Environment of The Folk Houses in Qingling Mountains. Acta Energiae Solaris Sinica.Vol.32(2011), p.171-174. 


\title{
The residential selection based on fuzzy multi-objective decision
}

\author{
Lin Zhang, Ke Wu, Di Xia \\ College of Mathematics and Information Science, Nan Chang Hang Kong University, 330063, Nan \\ Chang, Jiangxi, China
}

zhjiaoxue@163.com,wwkkdl@163.com, 1017112852@qq.com

\begin{abstract}
Keywords: Transportation Engineering; fuzzy multi-objective; membership functions; Borda function; fuzzy nearness

Abstract. In order to explore the process of residential selection, the fuzzy closeness degree of the interaction between the residential area and the target of location were proposed by the fuzzy quantitative treatment of all targets of location. According to the semantic evaluation of family satisfaction in each target, the fuzzy nearness degree matrix that community meets all the targets was established by the satisfaction. After the fuzzy comprehensive weights were proposed by the fuzzy ranking model, the highest satisfaction residence in the decision makers' heart was got by Borda functions. Examples show that: the residents from 23 to 30 years old will be as far as possible to select those districts that close to the destination and have lower prices, better entertainment environment. Residents with lower income from 31 to 45 years old will choose districts that have good education environment and lower prices. Low income residents from 46 to 59 years old, usually tend to choose those close to the destination, have lower prices, and close to the park, and have good natural and humanistic greening environment.
\end{abstract}

\section{Introduction}

With the rapid growth of China's economy and the accelerating process of urbanization, the constructing of a rational and sustainable development of urban traffic and the coordinated development of land use are becoming the focus on every urban planning. The types of land-use include industrial land, commercial land and residential land. Among them, the residential land is not only a large proportion of the total land use in the city, the intensity and efficiency when using land directly affect the overall amount of urban land. Therefore, it is an important basis for making the urban land-use policy to explore the process of residential selection.

At home and abroad, many experts and scholars have made a deeply study on the choice of residential location, and put forward different models. The space model proposed by Hansen and Lowry was distributed the residence by the gravity or entropy model [1]. Its advantage is that the application is simple, but the results cannot show the thought process of the residential selection well. A mathematical programming model [2] was designed to generate the optimal location of the family. The land-use system is composed of many subsystems, whose boundary is fuzzy, the logical relationship is complex. It is difficult to deal with the internal and external logic relations of the system through a mathematical programming model, the reliability of the results is reduced. The relationship between land use and transportation are revealed by the random utility model [3], and a lot of location indicators were used to describe the location characteristics, and it also reflects the behavior of individual decision-making process. However, the majority of those models using observation values extrapolated to reflect the relationship between transportation and land use, it existed model user's preference in data selection, and the selection and processing of index set may also have different degree of arbitrary.

This paper based on the fuzzy mathematics, combined the uncertain factors with the determined data, established the fuzzy multi-objective decision model, and analyzed the satisfaction of each residence, to explain the details of the behavior that the family decision makers choose the residence. 
During the study period, there are many families who need house-moving in a city, which form set $F$. Suppose that a city has a number of residential areas whose set is $D=\left\{d_{1}, d_{2}, \mathrm{~K} d_{n}\right\}$ and whose sum is $n$. When choosing where to live, any family $j \in F$ has some goals, such as convenient transportation, beautiful environment, complete facilities, good education and medical, good public security in surrounding areas and so on. Suppose that set $M_{j}=\left\{m_{1}^{j}, m_{2}^{j}, \mathrm{~L}, m_{s}^{j}\right\}$ represents the set of family housing targets, where $s$ is the target sum of the family $j$.

In reality, every family has a satisfaction evaluation about each goal of $M^{J}$. However, it's difficult to quantify these evaluations. Here we use fuzzy mathematics to process these semantic items. Let the extent that the residential area $d_{i}$ to meet the target $m_{q}^{j}$ of family $j$ is a fuzzy quantity, denoting as $\tilde{a}_{q i}^{j}$.The $\tilde{a}_{q i}^{j}$ here means the close degree of which meets the goal $m_{q}^{j}$.So the close degree that residential area $d_{i}$ to meet all targets which in the set $M_{j}$ form the vector $\left(\tilde{a}_{1 i}^{j}, \tilde{a}_{2 i}^{j}, \cdots \tilde{a}_{s i}^{j}\right)$, denoted as:

$$
\tilde{a}_{i}^{j}=\left(\tilde{a}_{1 i}^{j}, \tilde{a}_{2 i}^{j}, \cdots \tilde{a}_{s i}^{j}\right)^{T} .
$$

Among that: $\tilde{a}_{i}^{j}$ represents the close degree that residential area $d_{i}$ to meet all targets. Therefore, the close degree that all community in set $D$ to meet all targets of family $j$ is formed a fuzzy degree matrix $\tilde{A}^{j}$, denoted as:

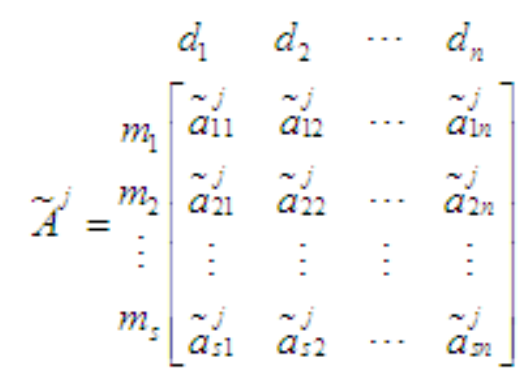

(1)

Here, ${ }^{, a_{q}^{j}}=\left(\tilde{a}_{q 1}^{j}, \tilde{a}_{q 2}^{j}, \cdots \tilde{a}_{q n}^{j}\right)$ represents the close degree of $n$ communities to meet the $j$ family's $q$ goal.

To give different weights according to the family's own characteristics in the process of choosing a place to live, here we introduce a weight vector. And denote the weight vector of Family $j$ 's $s$ goals as: $\widetilde{\sim}^{j}=\left(\widetilde{w_{1}}, \widetilde{w_{2}}, \cdots \widetilde{w}_{s}\right)^{T}$, where the $\widetilde{w}^{\sim}$ is the weight of the Family $j$ for the goal $q, q=1,2, \mathrm{~L} s$, and all ${ }^{\simeq j}$ are fuzzy numbers.

\section{The fuzzy membership functions}

Due to ${ }^{\tilde{a}_{\sigma}^{j}}$ and ${ }^{\simeq w_{q}}$ are fuzzy numbers, should not be compared directly to each other. We determine the alternate residential quarters by the fuzzy optimum seeking method. People choose where to live with some goals and expectations, every family has his expectations for each goal. Denote the fuzzy membership function of the location target $m_{q}^{j}$ as: 


$$
u_{\substack{o b \\ q i}}(x)= \begin{cases}\frac{x-l_{q i}^{j}}{n_{q i}^{j}-l_{q i}^{j}} & x \in\left[l_{q i}^{j}, n_{q i}^{j}\right] \\ \frac{v_{q i}^{j}-x}{v_{q i}^{j}-n_{q i}^{j}} & x \in\left(n_{q i}^{j}, v_{q i}^{j}\right] \\ 0 & x \in\left(-\infty, l_{q i}^{j}\right) \cup\left(v_{q i}^{j},+\infty\right)\end{cases}
$$

Set $\stackrel{0}{a}_{q i}^{j}=\left(l_{q i}^{j}, n_{q i}^{j}, v_{q i}^{j}\right)$. Where $l_{q i}^{j}$ is the lower bounds value that the decision maker evaluates the close degree. And, $n_{q i}^{j}$ is the expectations value, $v_{q i}^{j}$ is the upper bounds value. In the same way, denote the fuzzy membership function of weight ${ }^{\simeq}{ }^{j}$ of the target $m_{q}^{j}$ as: $\widetilde{\sim}_{q}=\left(l_{q}^{j}, n_{q}^{j}, v_{q}^{j}\right)$, where $l_{q}^{j}$ is the lower bounds value, $n_{q}^{j}$ is the expectations value and $v_{q}^{j}$ is the upper bounds value of the weight ${ }^{\simeq j}$.

\section{The optimal fuzzy decision model}

Assuming that similar properties family choose the same level of housing, and there is no cross when different kinds of families to choose the housing. In the same attribute decision-making group of the family, in terms of the target $m_{q}^{j}$, decision makers have a position in their mind for each residence, let $h(h=1,2, \mathrm{~L} n)$ represents the position of residence in the heart of decision makers. According to the fuzzy degree matrix $\tilde{A}^{j}$, if policymakers think the community $d_{r}$ should be in the $k$ place, and $h=k$, then let $\varphi_{r h q}^{j}=1, \operatorname{or} \varphi_{r h q}^{j}=0$. Therefore, the ranking matrix of residence that family $j$ for the target $m_{q}^{j}$ is $\Gamma_{q}^{j}=\left(\varphi_{r h q}^{j}\right)_{n \times n}$. To reflect decision-makers' preference to the housing, combined with the location $\varphi_{r h q}^{j}$ and weight $\tilde{w}_{q}^{j}$ of all target corresponding for the community $d_{r}$, and make a comprehensive summation, get the comprehensive ranking matrix $\tilde{B}^{j}=\left(\tilde{b}_{m}^{j}\right)_{n n}$ of the community $d_{r}$, here:

$$
\tilde{b}_{r h}^{j}=\sum_{q=1}^{m_{s}} \varphi_{m q}^{j} \underset{w_{q}^{j}}{\stackrel{\sim}{j}} \quad r=1,2, \cdots n, h=1,2, \cdots, n
$$

And, $\tilde{b}_{r n}^{j}$ is the comprehensive weights that decision makers $j$ give the community $d_{r}$, the more ,the better. ${ }^{\simeq}{ }^{\prime}$ is the fuzzy weighted.

According to (3), apply the Borda function, calculating the Borda choose function value of each residential area $d_{r}(r=1,2, \mathrm{~L}, n)$ given by the family decision makers $j(j \in F)$. The model is:

$$
B^{j}\left(d_{r}\right)=\sum_{t=1}^{n}(\mathrm{n}-\mathrm{t}) b^{b}
$$

Where $n$ is the total number of the alternative housing. Denote the Borda choose function value of each residence district given by the same attribute decision-making group as: 


$$
B\left(d_{r}\right)=\sum_{j=1}^{e} B^{j}\left(d_{r}\right)
$$

Where $e$ is the number of decision makers for the same attributes.

Compare the Borda function values and get the optimal residence for decision makers.

\section{Example}

Take the main city of Nanchang as the research object. Combined with the characteristics of the road network, Nanchang City will be divided into 25 residential areas, as shown in the figure1.And district 4, 15 are the downtown areas. People have seven major commuter destinations, they are district 2, 4, $9,15,17,18,22$. And district 1, 14, 16, 21, 23, 24 contain a park, residence 1 and 16 are the holiday leisure places, there are shopping malls in district 4,10,15, 19and key primary and secondary schools in district $3,10,13,15,20,21$.

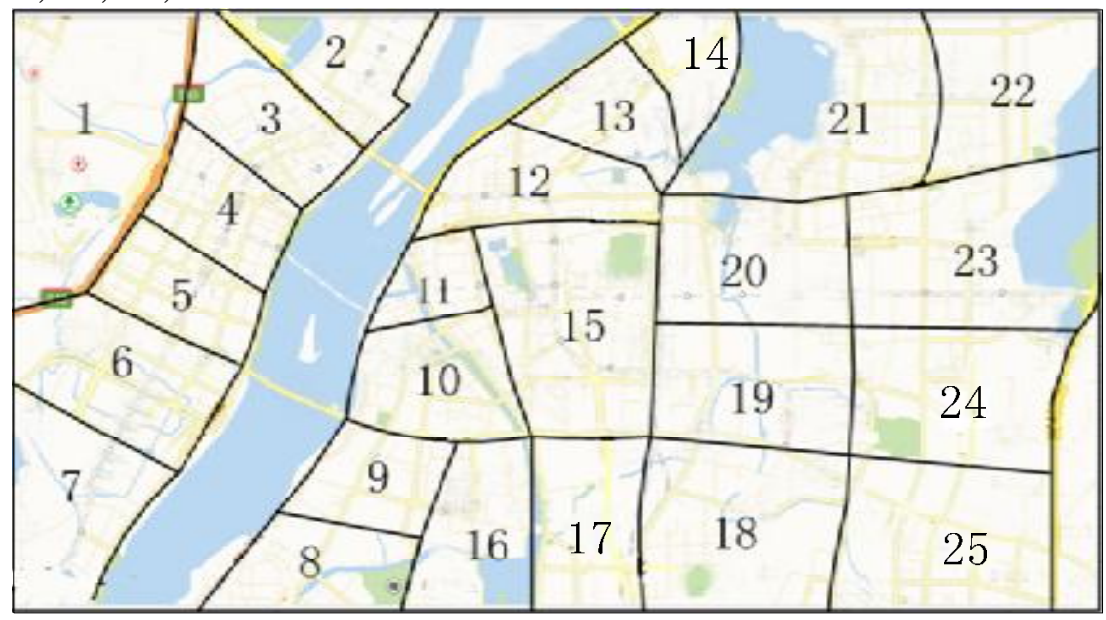

Fig1: District Division Figure of The Study Area

And as shown in the figure 1, there is a two-way road connection between adjacent residential area, the capacity of each other in the opposite direction and the free- flow speed of each road are the same, The width of the independent non-motor vehicle lane is 3 meters. The capacity of the main road is $7000 \mathrm{veh} \bullet \mathrm{h}-1$ and free-flow speed is $70 \mathrm{~km} \bullet \mathrm{h}-1$. The capacity of the Level 1 street is $5500 \mathrm{veh} \bullet \mathrm{h}-1$ and free-flow speed is $50 \mathrm{~km} \bullet \mathrm{h}-1$. The capacity of the Secondary street is $4000 \mathrm{veh} \bullet \mathrm{h}-1$ and free-flow speed is $40 \mathrm{~km} \bullet \mathrm{h}-1$.

Fig.2: Triangular Fuzzy Number

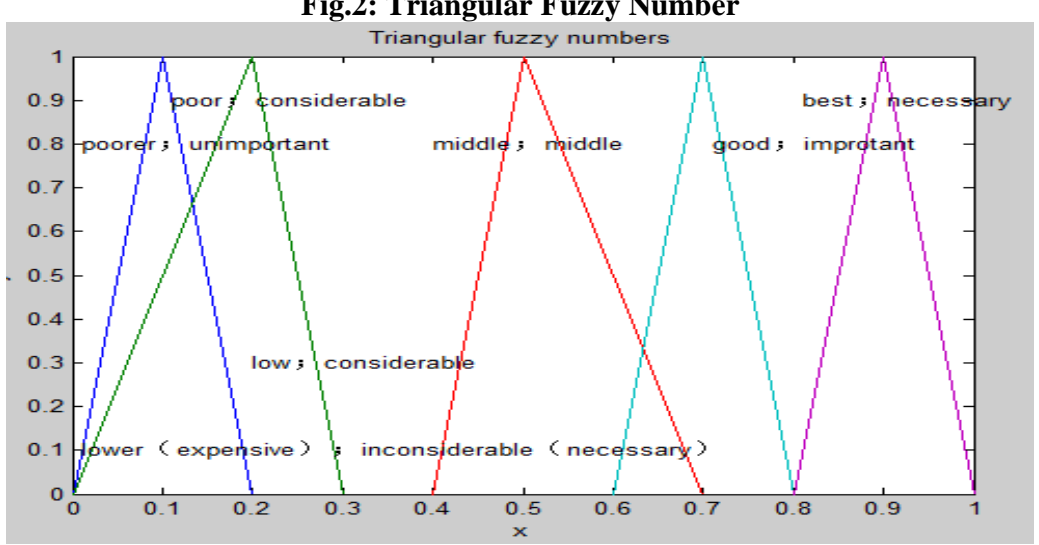


Table1: Preferences of Residents with Different Attributes When Choosing To Live

\begin{tabular}{|l|l|l|l|l|l|l|l|l|}
\multicolumn{2}{|l}{} & completeness & $\begin{array}{l}\text { population } \\
\text { density }\end{array}$ & environment & transportation & $\begin{array}{l}\text { housing } \\
\text { price }\end{array}$ & entertainment & education \\
\hline \multirow{4}{*}{$\begin{array}{l}\text { Age } \\
\text { groups }\end{array}$} & $23 \sim 30$ & important & important & important & $\begin{array}{l}\text { very } \\
\text { important }\end{array}$ & $\begin{array}{l}\text { very } \\
\text { important }\end{array}$ & $\begin{array}{l}\text { very } \\
\text { important }\end{array}$ & important \\
\cline { 2 - 8 } & $31 \sim 45$ & $\begin{array}{l}\text { More } \\
\text { important }\end{array}$ & $\begin{array}{l}\text { More } \\
\text { important }\end{array}$ & $\begin{array}{l}\text { very } \\
\text { important }\end{array}$ & important & important & considerable & necessary \\
\cline { 2 - 8 } & $46 \sim 59$ & very important & important & $\begin{array}{l}\text { very } \\
\text { important }\end{array}$ & considerable & important & so-so & important \\
\hline \multirow{3}{*}{$\begin{array}{l}\text { Income } \\
\text { level }\end{array}$} & low & imconsiderable & inconsiderable & considerable & $\begin{array}{l}\text { More } \\
\text { important }\end{array}$ & necessary & unimportant & important \\
\cline { 2 - 9 } & middle & important & important & important & $\begin{array}{l}\text { More } \\
\text { important }\end{array}$ & $\begin{array}{l}\text { More } \\
\text { important }\end{array}$ & important & necessary \\
\cline { 2 - 9 } & high & necessary & $\begin{array}{l}\text { More } \\
\text { important }\end{array}$ & necessary & unimportant & unimportant & necessary & necessary \\
\hline
\end{tabular}

Table2: The Fuzzy Evaluation of The Residential Areas and Each Target

\begin{tabular}{|c|c|c|c|c|c|c|c|c|c|c|c|c|c|}
\hline community & 1 & 2 & 3 & 4 & 5 & 6 & 7 & 8 & 9 & 10 & 11 & 12 & 13 \\
\hline completeness & better & good & better & best & better & better & good & well & good & best & good & good & good \\
\hline $\begin{array}{l}\text { population } \\
\text { density }\end{array}$ & good & good & good & 80-50 & good & good & good & well & well & $80-50$ & well & 50-50 & middle \\
\hline environment & good & better & better & best & better & better & good & middle & riddie & good & middle & 80-50 & poorest \\
\hline transportation & good & good & good & best & bettler & better & middle & $80-50$ & good & good & good & middie & good \\
\hline public secunity & better & bettier & bettier & best & best & better & better & middle & best & best & middle & middle & $50-50$ \\
\hline housing price & costly & costly & expensive & dear & costly & Costly & costly & middle & expensive & expensive & costly & costly & costly \\
\hline entertainment & better & $80-50$ & god & best & middle & midale & $50-50$ & $80-50$ & $50-50$ & good & good & good & middle \\
\hline education & $80-80$ & $50-50$ & best & good & good & middle & $50-30$ & $80-50$ & middle & best & middle & $50-50$ & best \\
\hline community & 14 & 15 & 16 & 17 & 18 & 19 & 20 & 21 & 22 & 23 & 24 & 25 & \\
\hline complateness & good & better & good & good & middle & good & midale & $80-50$ & good & good & $50-50$ & poor & \\
\hline $\begin{array}{l}\text { population } \\
\text { density }\end{array}$ & $50-50$ & pooler & middle & well & $50-50$ & $80-50$ & middle & $80-50$ & bettier & midale & good & good & \\
\hline environment & betier & middle & good & $80-50$ & poorest & riddie & 50-50 & good & better & good & good & $50-50$ & \\
\hline transportation & middle & best & middle & good & $80-50$ & $80-50$ & middle & poor & good & middle & middle & $80-50$ & \\
\hline public security & $80-50$ & middle & good & $80-50$ & middle & better & $50-50$ & good & middle & $80-50$ & $50-50$ & middle & \\
\hline housing price & costly & $\begin{array}{l}\text { expensi } \\
\text { ve }\end{array}$ & middle & middle & cheap & low & low & middle & costly & costly & midalle & low & \\
\hline entertainment & good & best & good & $80-50$ & poorer & good & pool & good & middle & $80-50$ & 50-50 & $80-50$ & \\
\hline education & middle & best & $50-50$ & $50-50$ & poor & poor & best & best & middle & $50-50$ & poor & poor & \\
\hline
\end{tabular}

According to the semantics evaluation of each area and the corresponding relationship between fuzzy evaluation, as shown in the table1, table2and figure 2, simulation model by MATLAB, we can get the following results of the best places to live in choice of family with different ages.

Table3: The Results of Low- income Residents from 23 to 30 Years Old Choose To Live

\begin{tabular}{|c|c|c|c|c|c|c|c|c|}
\hline Age groups & Destination & 2 & 4 & 9 & 15 & 17 & 18 & 22 \\
\hline \multirow[t]{2}{*}{$23 \sim 30$} & $\begin{array}{c}\text { The number of } \\
\text { low-income families }\end{array}$ & 844 & 914 & 1123 & 2256 & 1149 & 3585 & 3654 \\
\hline & Result of selection & 2 & 4 & 9 & 15 & 17 & 18 & 22 \\
\hline Age groups & Destination & 2,4 & 4,9 & 9,15 & 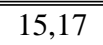 & 17,18 & 1818,22 & \\
\hline \multirow[t]{2}{*}{$23 \sim 30$} & $\begin{array}{c}\text { The number of } \\
\text { low-income families }\end{array}$ & 923 & 1003 & 1158 & 1231 & 2232 & 3492 & \\
\hline & Result of selection & 2 & 9 & 9 & 17 & 19 & 24 & \\
\hline \multicolumn{9}{|c|}{ Table4: The Results of Low- income Residents from 31 to 45 Years Old Choose To Live } \\
\hline Age groups & Destination & 2 & 4 & 9 & 15 & 17 & 18 & 22 \\
\hline \multirow[t]{2}{*}{$31 \sim 45$} & $\begin{array}{c}\text { The number of } \\
\text { low-income families }\end{array}$ & 844 & 914 & 1123 & 2256 & 1149 & 3585 & 3654 \\
\hline & Result of selection & 3 & 3 & 9 & 15 & 16 & 20 & 21 \\
\hline Age groups & Destination & 2,4 & 4,9 & 9,15 & 15,17 & 17,18 & 18,22 & \\
\hline \multirow[t]{2}{*}{$31 \sim 45$} & $\begin{array}{c}\text { The number of } \\
\text { low-income families }\end{array}$ & 923 & 1003 & 1158 & 1231 & 2232 & 3492 & \\
\hline & Result of selection & 3 & 9 & 10 & 20 & 20 & 20 & \\
\hline \multicolumn{9}{|c|}{ Table5: The Results of Low- income Residents from 46 to 59 Years Old Choose To Live } \\
\hline Age groups & Destination & 2 & 4 & 9 & 15 & 17 & 18 & 22 \\
\hline \multirow[t]{2}{*}{$46 \sim 59$} & $\begin{array}{c}\text { The number of } \\
\text { low-income families }\end{array}$ & 844 & 914 & 1123 & 2256 & 1149 & 3585 & 3654 \\
\hline & Result of selection & 2 & 1 & 9 & 16 & 17 & 18 & 22 \\
\hline Age groups & Destination & 2,4 & 4,9 & 9,15 & 15,17 & 17,18 & 18,22 & \\
\hline \multirow[t]{2}{*}{$46 \sim 59$} & $\begin{array}{l}\text { The number of } \\
\text { low-income families }\end{array}$ & 923 & 1003 & 1158 & 1231 & 2232 & 3492 & \\
\hline & Result of selection & 2 & 9 & 16 & 17 & 18 & 24 & \\
\hline
\end{tabular}

As shown in the table3, table 4, and table 5, the living location choice of residents with different age and income levels and the demand for living location factors are different. Residents from 23 to 
30 years old belong to the preference for the life, they pay more attention to the entertainment environment and the employment environment. Residents with the lower income and age levels as much as possible will be choose the district that close to commuter destination, have lower prices and good entertainment environment. Residents from 31 to 45 years old also belong to the lifestyle, but most of them have children, they pay more attention to the surrounding educational environment. Residents with lower income levels, the choice of residence can only be based on education environmental, they will choose the district that have good education environment and lower prices. Residents from 46 to 59 years old, belong to the preference for ecological, emphasize more on natural and humanistic greening environment around residential location. Low income families in these ages, usually tend to choose districts that are cheap, close to parks and have good natural and humanistic greening environment. Therefore, in the process of urban planning, the government and real estate developers should earnestly consider the different needs of residents with different attributes. In order to enhance the overall urban geographical advantages, they should be targeted to improve the residential location.

\section{Conclusions}

This article was based on the behavior characteristic of residence and concerned multi-objective attributes selections according to the different properties of residents, using fuzzy method to get the fuzzy evaluation of the location target. And a fuzzy multi-objective ranking model based on the residents' attributes was constructed to explore the process of residential selection. We can get the residential location and closeness degree of the target by fuzzy membership function. Synthesized the close degree and weight of the location object and we used Borda choice function to select out the residence where has the maximum satisfaction for different residents with different attributes. By means of fuzzy method, the decision-making process of people in residential selection was simulated, which can reflect human's thinking process. The model can provide the basis for the optimization of urban residential location structure and the purchase policy strategy. The next step is to explore the choice of the residence which contains the rail transit based on the fuzzy multi-objective and multi-person decision making.

\section{Acknowledgements}

This research is supported by National Natural Science Foundation of China under Grant No. 51368046 and Natural Science Foundation of Jiangxi Province of China under Grant No. 20151BAB201028.

\section{References}

[1] Abdul R P, Chandra R B, David A H. Residential self-selection effects in an activity time-use behavior model [J]. Transportation Research Part B, 2009(3), 43:729-748.

[2] Meloni I, Spissu E, Bez M. A model of the dynamic process of time allocation to discretionary activities[J]. Transportation Science, 2007, 41(1):15-28.

[3] Khattak A.J, Rodriguez D. Travel behavior in neo-traditional neighborhood developments:a case study in USA[J]. Transportation Research Part A, 2005, 39(6):481-500. 


\title{
The traffic mode choice model based on fuzzy order theory
}

\author{
Lin Zhang, Nana Lv , Ke Wu \\ College of Mathematics and Information Science, Nan Chang Hang Kong University, 330063, Nan \\ Chang, Jiangxi, China
}

zhjiaoxue@163.com, 286634603@qq.com, wwkkdl@163.com

\begin{abstract}
Keywords: attention point; travel attribute; fuzzy weight; traffic mode choice; fuzzy order method Abstract: In order to investigate the effect of traffic mode choice for travel attributes from travel attention point, the multi-objective fuzzy order model was established for different travelers by fuzzy methods. Considering the travelers' ages, careers, and other factors, all kinds of travelers' travel attention point weights and close degrees were obtained by using triangular fuzzy numbers. The traffic order values were obtained and travelers got the preferred traffic mode by constructing the fuzzy order choice mode. The example indicates that below 35 years old and over 60 travelers, bus or subway was the first choice, 36 to 59 years old travelers preferred transportation was private cars. The decision process of the choice of traffic mode was simulated by the fuzzy method, the research of model could provide the basis for urban traffic structure optimization and transportation policy strategy.
\end{abstract}

\section{Introduction}

The travelers' traffic mode choices determine the structure of the urban traffic in a large extent. With the development of economy and urbanization, residents can choose diverse traffic modes. According to the travel attributes, a reasonable choice of traffic mode is a necessary way to ease urban traffic congestion problems.

Many research about the traffic mode choice were developed ,many different models and algorithms were gave out, and gave out different models and algorithms[1,2]. Ben et al analyzed the traffic mode choice by using discrete form, and established the traffic demand model[3]. According to different influence on travel factors to traffic mode choices, Wallace et al constructed a negative two regression model[4]. The relevant policies of Traffic Demand Management (TDM) were made by the relative effects of the travel attributes to travel behavior. These models described the factors influencing the traffic mode choice by the precise number, but many factors were involved and difficult to quantified. So there are some limitations.

Fuzzy mathematics[5] enable the study of the mathematics communication between mathematical certainty objects and mathematical uncertainty by certain fuzzy objects with the fuzzy set theory. Therefore, the fuzzy multi-objective attribute model for different types of travelers is established by combining the uncertain factors of affecting traffic choice and the deterministic data based on the fuzzy mathematics, and the fuzzy multi-objective model is solved by using the fuzzy order method. It explains behavior details of travelers choose traffic modes.

\section{The attention point}

In a city let $N=\{1,2, \mathrm{~L}, n\}$ be a set of all travelers, where the total number of travelers is $n$. Before the trip, travelers have fast, province, convenient, comfortable, safety attention points. Assume that the traveler has $z$ attention points, and make $h_{i}^{k}$ the first attention point of $i$ for the traveler $k$, where $0<i \leq z$ and $i$ is an integer. Let $M=\{1,2, \mathrm{~L}, m\}$ represents a set that the travelers' choice of traffic mode consisting of, which $m$ is the sum number of traffic modes. 
For any traffic mode $j \in M$, the traveler $k \in N$ chooses the traffic mode $j$ to satisfy the degree of $h_{i}^{k}$ for the attention point $h_{i}^{k}$, it is a fuzzy quantity, and noted the fuzzy number, ${ }^{\tilde{h}_{i j}^{k},} \tilde{h}_{i j}^{k}$ represents a close degree that the traffic mode $j$ achieve $k$ 's attention point $h_{i}^{k}$.

\section{The travel attribute and fuzzy weight}

Since different travelers for the same attention point of the importance of evaluation is different, so according to the importance of travelers' own individual attention points, travelers give different attention points corresponding weights. Let the fuzzy weight vector of the traveler $k$ to all attention points is:

$$
\tilde{\lambda}^{k}=\left(\tilde{\lambda}_{1}^{k}, \tilde{\lambda}_{2}^{k}, \cdots, \tilde{\lambda}_{z}^{k}\right)^{\mathrm{T}}
$$

where $\tilde{\lambda}_{i}^{k}(i=1,2, \cdots, z)$ is the weight that the traveler $k$ to the attention point $h_{i}^{k}$, and ${ }^{\tilde{\lambda}_{i}^{k}}$ is the fuzzy number.

Travelers' ages and careers are different, the fuzzy weights are often different.

The influence of ages on attention points: the different ages of the travelers, the attention degree to the attention point is different. So according to travelers' ages, the corresponding weight evaluations to the attention points are given. Suppose that set $S=\{1,2, \mathrm{~L}, s\}$ represents age groups of all travelers, for any age group $q \in S$, the attention degree of the travelers belonging to the $q$ age group to the attention point $i$ is a fuzzy quantity, and marked $\tilde{w}^{q}$.

The influence of careers on attention points: the different careers of the travelers, the preference degree to the attention point is different. The careers can be divided into students, civil servants, managers, ordinary workers, unemployed retirees and so on. Let $G=\{1,2, \mathrm{~L}, g\}$ be a set that occupation classifications of all travelers, For any occupation classification $t \in G$, the preference degree to the attention point $i$ is a fuzzy quantity, and denoted as $\% / c$.

For any traveler $k \in N$, the comprehensive index to the weight of the attention point $h_{i}^{k}$ can be marked by multiplying the attention degree $\mathfrak{q}_{i}^{q}$ and the preference degree $q$ \%

$$
\tilde{\lambda}_{i}^{k}=\tilde{w}_{i}^{q} \times \tilde{l}_{i}^{t}
$$

Here, ${ }^{\tilde{\lambda}_{i}^{k}}$ represents the comprehensive evaluation index of the traveler $k$ that $q$ group of ages and $t$ kind of careers to the attention point $h_{i}^{k}$.

\section{The fuzzy multi-objective order method}

The process of travelers choose traffic modes naturally is a multi-objective decision problem. In order to judge the merits of each traffic mode to an attention point, the following the merits of $M$ traffic modes are confirmed by using the fuzzy optimization method.

There are a number of attention points when travelers choose traffic modes, and these attention points are corresponding to the expectation values. The evaluation of the traveler $k$ to the close degree $h_{i j}^{k}$ more approaches the expectation value, then the fuzzy membership degree more 
approaches one, so the fuzzy membership degree of the close degree $h_{i j}^{k}$ to the attention point $h_{i}^{k}$ by the triangle fuzzy number is expressed as:

$$
u_{\text {嚓 }}(x)=\left\{\begin{array}{cl}
\frac{x-a_{i j}^{k}}{b_{i j}^{k}-a_{i j}^{k}} & x \in\left[a_{i j}^{k}, b_{i j}^{k}\right] \\
\frac{c_{i j}^{k}-x}{c_{i j}^{k}-b_{i j}^{k}} & x \in\left(b_{i j}^{k}, c_{i j}^{k}\right] \\
0 & \text { others }
\end{array}\right.
$$

It's noted $\tilde{h}_{i j}^{k}=\left(a_{i j}^{k}, b_{i j}^{k}, c_{i j}^{k}\right)$, which $a_{i j}^{k}$ is the lower bound value of the traveler $k$ the close degree $h_{i j}^{k}$; $b_{i j}^{k}$ and $c_{i j}^{k}$ respectively is the expectation and upper bound value.

The attention degree $\tilde{w}^{\tilde{q}}$ and the preference degree $\tilde{l}_{i}^{t}$ are the fuzzy numbers, and their triangular

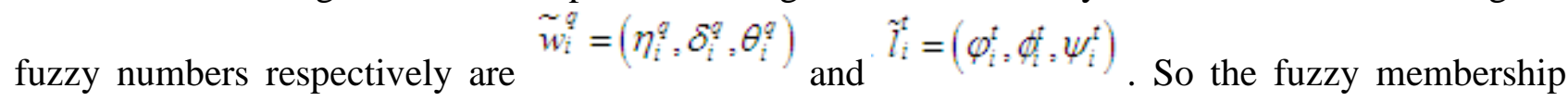
degree of the standardized fuzzy weight $\chi_{i}^{k}$ is expressed as:

$$
\chi_{i}^{k}=\left(\eta_{i}^{q} \varphi_{i}^{t}, \delta_{i}^{q} \phi_{i}^{t}, \theta_{i}^{q} \psi_{i}^{t}\right)
$$

where $\eta_{i}^{q} \varphi_{i}^{t}, \quad \delta_{i}^{q} \phi_{i}^{t}$ and $\theta_{i}^{q} \psi_{i}^{t}$ respectively represents the lower bound, expectation upper bound value of the evaluation to the weight $\tilde{\hat{\lambda}}^{k}$.

The fuzzy multi-objective decision mainly solves the comprehensive evaluation to the choice of the traffic mode, the purpose is to make the overall evaluation of the traveler $k$ choices the traffic mode $j$, which form a new comprehensive index by being combined with the corresponding close degree $^{\tilde{h}_{i j}^{k}}$ and the weight $\tilde{\lambda}_{i}^{k}$. The close degree $\tilde{h}_{i j}^{k}$ and the weight $\tilde{\lambda}^{k}$ is weighted aggregated. Namely,

$$
\tilde{r}_{i j}^{k}=\tilde{\lambda}_{i}^{k} \times \tilde{h}_{i j}^{k}
$$

Among that , $\tilde{r}_{\ddot{j}}^{k}=\left(\eta_{i}^{q} \varphi_{i}^{t} a_{i j}^{k}, \delta_{i}^{q} \phi_{i}^{t} b_{i j}^{k}, \theta_{i}^{q} \psi_{i}^{t} c_{i j}^{k}\right)$.

According to the weighted aggregation ${ }^{\tilde{r}_{i j}^{k}}$, the comprehensive evaluation value of the traffic mode $j$ is obtained by summing all the attention points of ${ }^{\tilde{r}_{i j}^{k}}$.

$$
\tilde{Y}_{j}^{k}=\sum_{i=1}^{z} \tilde{r}_{i j}^{k} \quad j=1,2, \ldots, m ; k=1,2, \cdots, n
$$

Thus, the fuzzy membership degree about the comprehensive evaluation value $\tilde{Y}^{k}$ is:

$$
\tilde{Y}_{j}^{k}=\left(y_{j 1}^{k}, y_{j 2}^{k}, y_{j 3}^{k}\right)
$$


Here, $y_{j 1}^{k}=\sum_{i=1}^{z} \eta_{i}^{q} \varphi_{i}^{t} a_{i j}^{k}, y_{j 2}^{k}=\sum_{i=1}^{z} \delta_{i}^{q} \phi_{i}^{t} b_{i j}^{k}, y_{j 3}^{k}=\sum_{i=1}^{z} \theta_{i}^{q} \psi_{i}^{t} c_{i j}^{k} ; y_{j 1}^{k}, y_{j 2}^{k}$ and $y_{j 3}^{k}$ respectively is the lower bound, expectation and the upper bound value.

Next, the comprehensive evaluation values are ordered. The expectation value more can reflect the comprehensive evaluation, so the traffic order values are obtained by using the average area. There is a sort $P^{k}$ of all traffic modes. Namely,

$$
P^{k}\left(\widetilde{Y}_{j}^{k}\right)=\frac{y_{j 1}^{k}+y_{j 2}^{k}+y_{j 3}^{k}}{3}
$$

The merit order of the traffic modes is obtained by the above analysis calculation, the traveler $k$ thereby chooses the best traffic mode.

\section{Example}

For example, the ages, occupations and trip purposes of travelers in a city are divided into four segments, five categories and four categories respectively. Travelers' attention points are divided into five categories: economy, accessibility, convenience, comfort and security. The corresponding evaluations of different attribute travels to the attention points are obtained by telephone interviews and other methods. As shown in Table 1.

Table1 Semantic Items of Travel Attention Points Evaluation for travelers with different attributes

\begin{tabular}{|c|c|c|c|c|c|c|}
\hline & & Economy & Accessibility & Convenience & Comfort & Safety \\
\hline \multirow{4}{*}{ Age groups } & $1: 10 \sim 18$ ages & $\begin{array}{c}\text { Less } \\
\text { important }\end{array}$ & Important & Important & $\begin{array}{c}\text { Less } \\
\text { important }\end{array}$ & $\begin{array}{c}\text { Very } \\
\text { important }\end{array}$ \\
\hline & $2: 19 \sim 35$ ages & $\begin{array}{c}\text { Very } \\
\text { important }\end{array}$ & $\begin{array}{c}\text { Very } \\
\text { important }\end{array}$ & Not important & $\begin{array}{c}\text { Not } \\
\text { important }\end{array}$ & Medium \\
\hline & $3: 36 \sim 60$ ages & $\begin{array}{c}\text { Not } \\
\text { important }\end{array}$ & Important & Not important & Important & Important \\
\hline & $4:$ over 60 ages & $\begin{array}{c}\text { Less } \\
\text { important }\end{array}$ & Not important & $\begin{array}{c}\text { Very } \\
\text { important }\end{array}$ & Important & $\begin{array}{c}\text { Very } \\
\text { important }\end{array}$ \\
\hline \multirow{5}{*}{$\begin{array}{l}\text { Occupational } \\
\text { groups }\end{array}$} & 1 : Civil servant & Medium & Important & Important & $\begin{array}{c}\text { Less } \\
\text { important }\end{array}$ & Medium \\
\hline & $\begin{array}{c}2: \text { Enterprises } \\
\text { personnel }\end{array}$ & Important & $\begin{array}{c}\text { Very } \\
\text { important }\end{array}$ & Medium & $\begin{array}{c}\text { Not } \\
\text { important }\end{array}$ & $\begin{array}{c}\text { Less } \\
\text { important }\end{array}$ \\
\hline & $\begin{array}{c}3: \text { Individual } \\
\text { owners }\end{array}$ & Important & Medium & Important & $\begin{array}{c}\text { Less } \\
\text { important }\end{array}$ & $\begin{array}{c}\text { Not } \\
\text { important }\end{array}$ \\
\hline & 4 : Students & $\begin{array}{c}\text { Not } \\
\text { important }\end{array}$ & $\begin{array}{c}\text { Very } \\
\text { important }\end{array}$ & Medium & $\begin{array}{c}\text { Not } \\
\text { important }\end{array}$ & $\begin{array}{c}\text { Very } \\
\text { important }\end{array}$ \\
\hline & $\begin{array}{c}5: \text { Unemployed } \\
\text { retirees }\end{array}$ & $\begin{array}{c}\text { Very } \\
\text { important }\end{array}$ & Not important & Medium & $\begin{array}{c}\text { Less } \\
\text { important }\end{array}$ & Medium \\
\hline
\end{tabular}

Let $\mathrm{K}_{\mathrm{qtd}}$ show the traveler that $\mathrm{q}(\mathrm{q}=1,2,3$ or4 $)$ age group and $\mathrm{t}(\mathrm{t}=1,2,3,4$ or5 $)$ occupational group. According to the different ages and occupations, there are 11 types of travelers $(1+5+4+1=11)$.

Travelers can choose traffic modes by bus, subway and private car. Each type of travelers to various traffic mode has a semantic evaluation. Assume that students don't have private cars, then the corresponding semantic evaluation close degree is assigned zero.

In order to quantify the above semantic evaluation, the fuzzy triangle number of the semantic items is given. 
Fig.1 Semantic Evaluation of traffic mode Merits and travel attention Points corresponding the Triangular Fuzzy Numbers

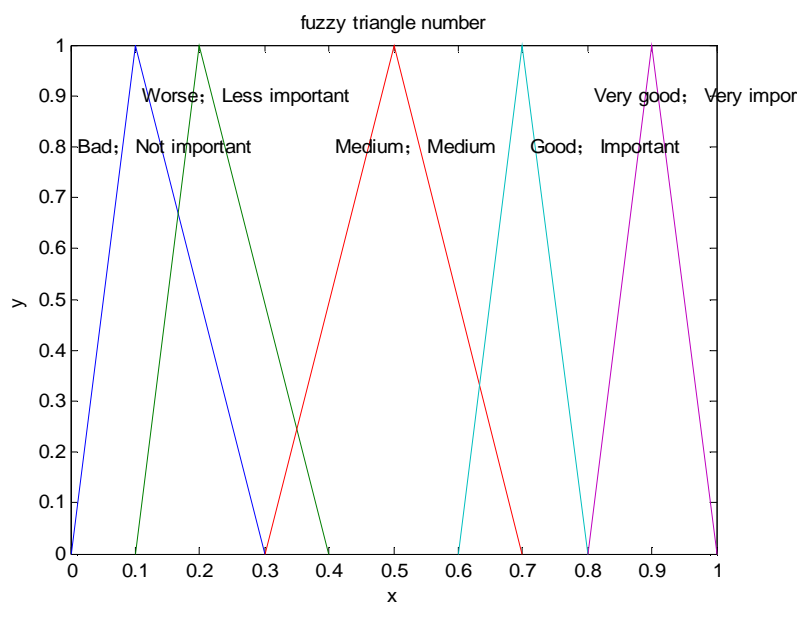

The table 1 and the figure 1 showed that the corresponding weight triangle fuzzy numbers of different attention points were obtained.

In order to convenient drawing, it's numbering types of traveler now. Table2 is the corresponding relation between serial numbers and types of travelers.

Table2 The Corresponding Relation between serial numbers and types of travelers

\begin{tabular}{|c|c|c|c|c|c|c|c|c|c|c|c|}
\hline Numbers & 1 & 2 & 3 & 4 & 5 & 6 & 7 & 8 & 9 & 10 & 11 \\
\hline Types & $\mathrm{K}_{14}$ & $\mathrm{~K}_{21}$ & $\mathrm{~K}_{22}$ & $\mathrm{~K}_{23}$ & $\mathrm{~K}_{24}$ & $\mathrm{~K}_{25}$ & $\mathrm{~K}_{31}$ & $\mathrm{~K}_{32}$ & $\mathrm{~K}_{33}$ & $\mathrm{~K}_{35}$ & $\mathrm{~K}_{45}$ \\
\hline
\end{tabular}

The traveler will be more inclined to choose this traffic mode of the higher order value. The order values of all 11 types of travelers to traffic modes are obtained by the number in Table 2 as the horizontal ordinate, marked the types of travelers, the order values as longitudinal coordinate.

Fig.2 Order Values of All Transportation Modes for travelers

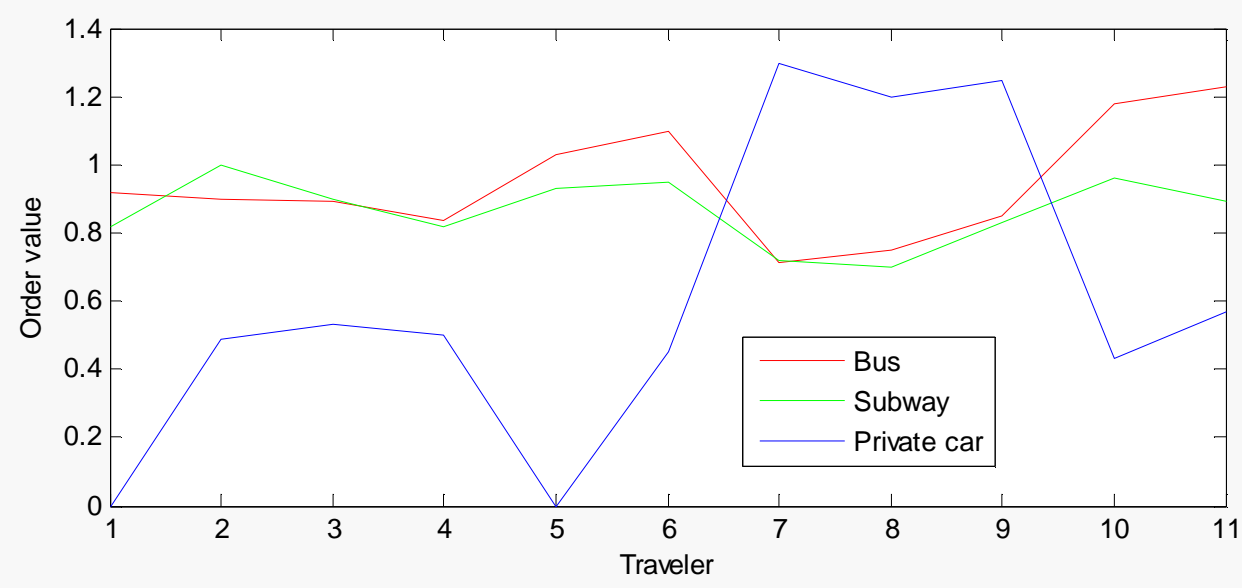

From the figure 2, the bus and subway of travelers below 35 years old order values were higher, distributing between 0.8 to 1.2 ; the private car of travelers 36 to 59 years old order (in addition to leaving staffs)value was higher, distributing between1 to 1.3; the bus and subway of travelers over 60 order values were higher, distributing between 1.2 to 1.3 . Bus was the students and retirees preferred traffic mode. The order values were above 0.9 .

\section{Conclusion}

In this paper, the multi-objective fuzzy attribute model were established by obtaining the fuzzy numbers of travel attributes and attention points. According to quantifying different traffic modes, the order to traffic modes was obtained. Based on the above analysis, the decision-making process of the choice of traffic mode was simulated by the fuzzy method, and reflecting the process of thinking, the research of model could provide the basis for urban traffic structure optimization and 
transportation policy strategy. The next step is to analyze the influence of the choice of traffic modes from the point of view of travel time, income level and the changes of urban traffic policy.

\section{Acknowledgements}

This research is supported by National Natural Science Foundation of China under Grant No. 51368046 and Natural Science Foundation of Jiangxi Province of China under Grant No. $20151 \mathrm{BAB} 201028$.

\section{Reference}

[1] Garling Tommy, Kwan M P, Golledge R G. Computational-process modeling of household activity scheduling [J]. Transportation Research B,1994,28(5):355-364

[2] Jou Rongchang, Chen Chih-Cheng, Chen, Yung-Lin. The effects of travel satisfaction of unimplemented transportation demand management strategies on travel behavior [J]. Transportmetrica, 2011, 7(7):201-228.

[3] M.E., Ben-Akiva, S.R., Leman. Discrete choice analysis: theory and application to travel demand [J]. Operational Research Society,1987,38(4):370-371.

[4] Wallace B., Barnes J., Rutherford G.S.. Evaluating the effects of traveler and trip characteristics on trip chaining, with implications for transportation demand management strategies [J]. Transportation Research Record Journal of the Transportation Research Board, 2000,1718(1):97-106.

[5] Li Deng-feng. Fuzzy Multi-objective Many-Person Decision Makings and Games[M]. Beijing: National defence industry Press,2002. 


\title{
Application of CFRP Suspenders for Through and Half-through Arch Bridges
}

\author{
Jing Gao', a, Bin Zhao', b \\ ${ }^{1}$ Civil Engineering, Xiamen University, Xiamen, China \\ agaojing@xmu.edu.cn, bxmu09zb@163.com
}

\begin{abstract}
Keywords: Application, Arch bridge, CFRPs, Suspender
Abstract. Through and half-through arch bridges are modern bridge types due to the development of steel as a building material, in which up to now the dead-load of the deck system and the live load are transferred to the arch rib by steel suspenders. However such suspenders are due to complex mechanical loading patterns and atmospheric attacks suffering fatigue, fretting fatigue, stress corrosion and corrosion. In the past decade, even bridge decks collapsed due to these problems. Realizing the excellent properties of carbon fiber reinforced polymers (CFRPs), including corrosion resistance, very high specific strength and stiffness, and outstanding fatigue behavior, the application of CFRPs for suspenders will be a good choice. In this paper, the bridge deck collapses due to broken steel suspenders will be reviewed, and a proposal for the application of CFRP suspenders for arch bridges will be introduced.
\end{abstract}

\section{Introduction}

Through and half-through arch bridges are modern bridge types due to the development of steel as a building material, in which up to now the dead-load of the deck system and the live load are transferred to the arch rib by steel suspenders. Therefore, suspenders become the most critical load-carrying members. However such suspenders are due to complex mechanical loading patterns and atmospheric attacks suffering fatigue, fretting fatigue, stress corrosion and corrosion. They require a high fatigue and corrosion resistance and have to be easy to install at low cost. Currently, the suspenders are made of steel rods, high-strength steel wires or steel strands. The types of anchorages at either termination directly determine the application feasibility of suspenders in bridge constructions, for which the anchorages play a decisive role in achieving an optimal exploitation of the steel tendons.

Suspenders are suffering due to much more increased corrosion and fatigue loading. The excellent properties of carbon fiber-reinforced polymer (CFRP) has got widely attention, including corrosion resistance, very high specific strength and stiffness, and outstanding fatigue behavior. Empa researchers were developing several anchorage systems for unidirectional CFRP tendons.

\section{The Situation in China Today}

Suspenders are subjected to corrosion, high tensile forces and high stress variations. It has become the key element for the long term reliability and safety in the design of half-through and through arch bridges. In the following sections we will discuss the problems with metallic suspenders.

Corrosion. Corrosion is one of worldwide the most severe challenges for suspenders and stay cables. About twenty years ago the construction of arch bridges with suspenders began in China. And it has grown dramatically since the early 2000s. The corrosion protection of the suspenders in many instances was not sufficient in early stages. Even now designers are still not satisfied with the results that no one can ensure the measures work effective for the long term serve. After only 5 to 10 years of service, corrosion and fatigue problems appeared in a number of cases in the suspenders, which became a potential danger for some bridges.

For certain classes of steel high sustained stresses might also cause the dangerous stress-corrosion, which is difficult to detect.

Fatigue. Suspenders are under both the action of high tensile forces and high stress variations. But designers always paid much attention to the strength requirements and often neglected fatigue. The 
vehicle-induced vibrations, impact, and subsidiary stress resulting from wind, wind-rain, vortex, and galloping oscillations, as described by DIN (2007) in the German recommendation "Design rules for suspenders of through arch bridges", have mostly been ignored in the suspender design. High fatigue resistant components are of great importance for the long term reliability and the safety of the suspender system. To some extent, the durability of a half-through and through arch bridge relies much on the suspender fatigue resistance.

Fretting fatigue. In the region, where the steel wires get first in touch with the grout, there is during the first loading a concentration of the shear stresses at the wire surface. The ASM "Handbook on Fatigue and Fracture" defines wear and fretting fatigue as: "A special wear process that occurs at the contact area between two materials under load and subject to minute relative mo-tion by vibration or some other force." Such fretting fatigue might happen on the load side of sockets grouted with epoxy or even more critical with cement mortar. Due to this high shear stresses there is debonding of the wires from the grout over a length of some few millimeters. Under fatigue loading there will be a relative displacement between the edges of the grout and the wires.

Superimposed bending stress. Generally, there is a special problem on the shortest suspender, which is located near to springing of the arch and has a very short free length. It results in the high bending stiffness. Horizontal relative displacements between the top and bottom ends of the suspenders lead to additional bending moments. With these bending moments superimposed to the normal stresses, there might be a three-dimensional stress state. It is especially dangerous in the case of fatigue. In addition, the temperature variation will also have great effect on the short suspender.

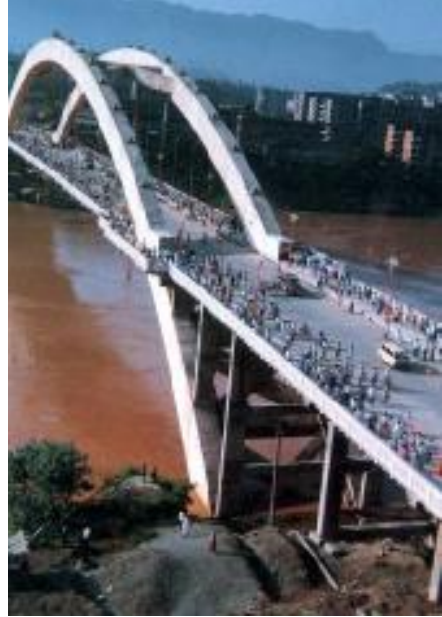

Figure. 1: Xiao-nan-men Bridge Figure. 2: Xiao-nan-men Bridge after the collapse

Case study Xiao-nan-men Bridge. Xiao-nan-men Bridge is a half through reinforced concrete arch bridge with a total length of $387 \mathrm{~m}$, which was built in 1984 and opened to traffic in 1990 . The bridge before the collapse is shown in Fig. 1. In the early morning about 4:00a.m on Nov.7, 2001, the deck of Nan-men Bridge, about $40 \mathrm{~m}$ in the south and $20 \mathrm{~m}$ in the north, was partly collapsed due to several pairs of broken suspenders. Fig. 2 shows the bridge after the collapse.

After the collapse, the bridge site was investigated. Fig. 3 shows the details of the failure suspenders. There were totally four pairs of suspender broke, three pairs in the south and one in the north. The corrosion of the wires was very obvious. Parts of the corrosion protection had been in failure. It was found that all failures of the broken suspenders were in the vicinity of the bottom sockets connected to the deck. Testing of the main arch rib shows that the arch rib was stable, and cracks on the arch rib had no effect on the entire behavior of the rib. Therefore, it was decided to replace all suspenders while the original arch ribs could be utilized. Then it was opened to the public for traffic as normal on June 28th, 2002. 

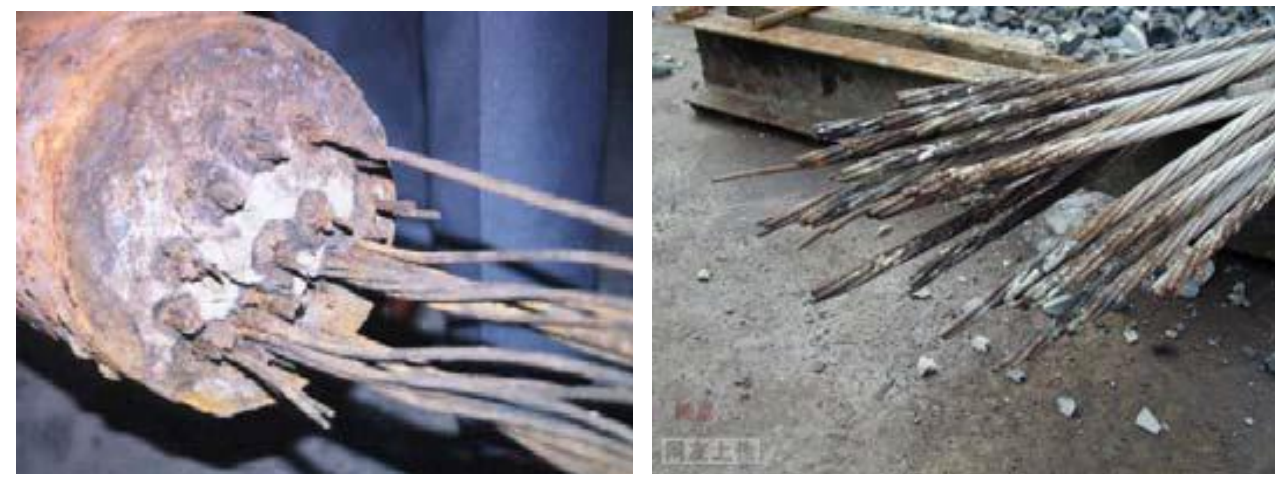

Figure. 3: Details for the broken wires of Xiao-nan-men Bridge

Case study Kong-que-he Bridge. Kong-que-he Bridge (Peacock River Bridge) in Xin-jiang was a half-through concrete filled steel tubular arch bridge with the main span of $150 \mathrm{~m}$ and width of $24.5 \mathrm{~m}$. The rise-to-span ratio of the bridge was $1 / 4.5$. The deck system, consisted of $5.0 \mathrm{~m}$ and $7.5 \mathrm{~m}$ span reinforced concrete T-shaped girder, was suspended below the truss arch rib by 23 pairs of suspender. The bridge was opened to traffic in August, 1998. A part of the deck in Kong-que-he Bridge collapsed and dropped into the river at 5:30a.m on Apr. 12th, 2011. Fig. 4 shows the bridge after the collapse. Because of the deck collapse, the Kong-que-he Bridge was closed to traffic forever. It had been in service for only 13 years, which is very far from its design lifetime.

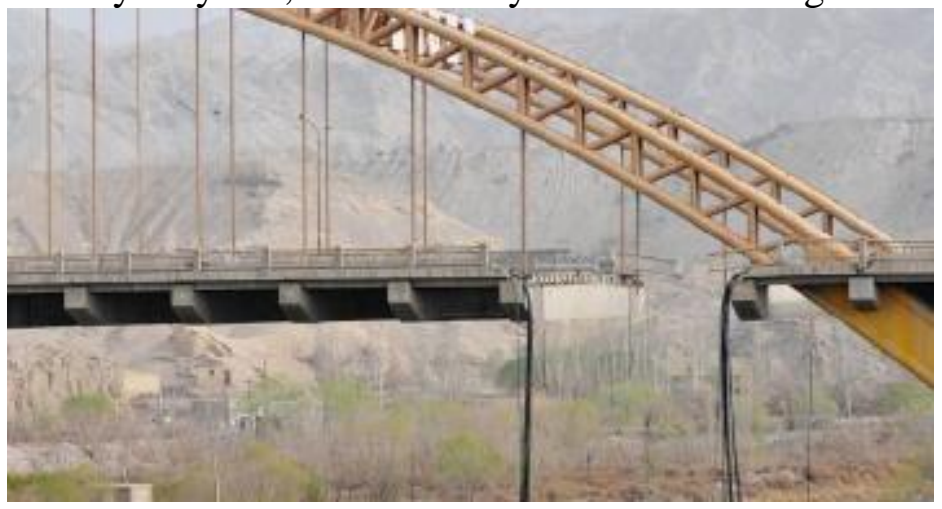

Figure. 4: Kong-que-he Bridge after collapse in 2011

Case study Gong-guan Bridge. Gong-guan Bridge is located in Wu-yi-shan Scenic Area, Fujian, which was open to traffic Nov.20, 1999. It is a half-through reinforced concrete arch bridge with three spans, $80 \mathrm{~m}+100 \mathrm{~m}+80 \mathrm{~m}$. At $8: 50 \mathrm{a}$.m on July 14, 2011, when a tourist bus and an overloading truck were passing the bridge, the deck of the first span partly collapsed as a result of broken suspenders. Fig. 5 shows the bridge before and after collapse.

The bus dropped into the river with 22 injured and the driver dead. However, the truck, having self-weight of $20.6 \mathrm{t}$ and carrying $60 \mathrm{t}$ sand, was the direct reason for the collapse, because the nominal carrying capacity of the truck is only 15.65t. The load on the truck was nearly four times of its nominal capacity. The overloading truck may be the obvious reason for the collapse. But the bridge is located in a very important road and had heavy traffic. Many overloading vehicles passed the bridge every day, which resulted in the damage of suspenders to varied degrees.

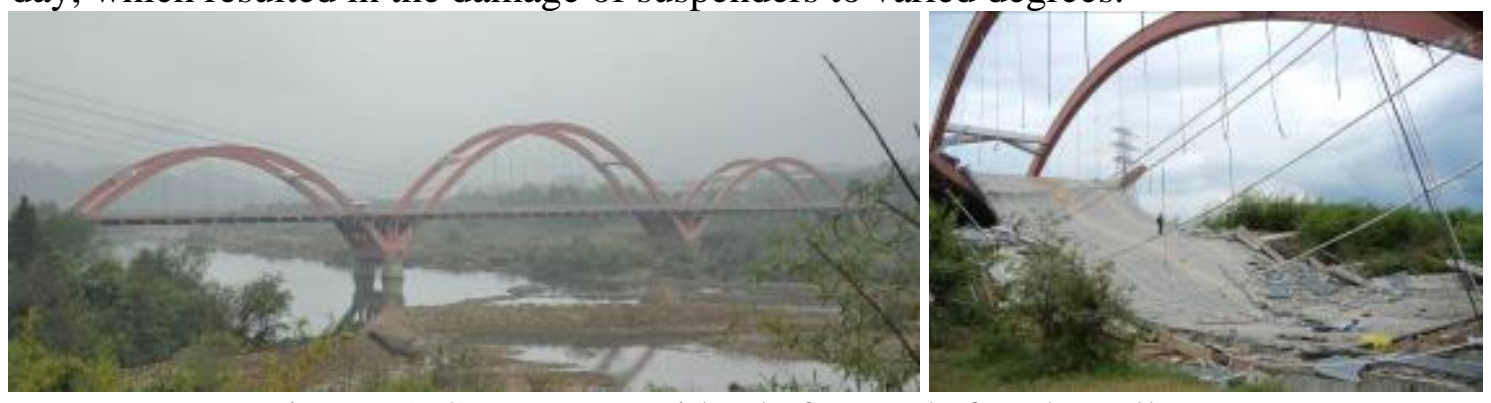

Figure. 5: Gong-guan Bridge before and after the collapse 


\section{Proposal for the Application of CFRP Suspenders}

Fatigue and corrosion related problems are the main reasons for the failures of suspender cables. Corrosion could be avoided with suspenders made of stainless steel or carbon fiber reinforced polymers (CFRP). CFRP is much better on the performance of fatigue than stainless steel. Suffering no stress corrosion, CFRP has been demonstrated the outstanding fatigue which is instrumental for the application for suspenders, in contrast to several stainless steels by EMPA.

EMPA researchers has developed several anchorage systems, which made it possible for the application of CFRP in suspenders or cables. Meier (2012) described the development of a gradient anchorage system for parallel CFRP wire/strand bundles and its application for stays and for post-tensioning cables. The load capacity of this system ranges from $60 \mathrm{KN}$ to $25 \mathrm{MN}$. It has successfully been applied for stay andpost-tensioning cables since seventeen years. Such tendons have been loaded with sustained loads corresponding to stresses higher than $1600 \mathrm{MPa}$. There is a comprehensive monitoring on such tendons and other load carrying CFRP applications in bridge engineering since 1991 de-scribed by Meier, Brönnimann, Anderegg, and Terrasi (2013). All results are very satisfactory

A "pin-loaded CFRP strap system" has been developed at EMPA by Winistörfer (1999) for load capacities up to $3 \mathrm{MN}$, for the gradient anchorage system for parallel CFRP wire/strand bundles is relatively expensive. While this system is very efficient and easy to handle. Originally it was intended for active shear strengthening applications as described by Lees, Winistörfer, and Meier (2002). Since ten years it has been used successfully for the strengthening of historical structures, and most important, for corrosion free, lightweight and fatigue resistant tendons for duty cycle crawlers of the Liebherr Company. This application is, considering the fatigue load spectra, very similar to that of bridge suspenders.

Application for Dongmen Bridge. Dongmen Bridge is a concrete-filled steel arch bridge with a span of $62 \mathrm{~m}$ and a width of $21.8 \mathrm{~m}$. The rise-to-span ratio of the bridge was $1 / 4$. It includes 26 steel cables anchored under the arch ribs and up on 13 horizontal beams. We have applied the computer models to replace the 26 steel suspenders by CFRP cables in numerical method. Then we compared the response of the bridge using CFRP suspenders with the original arch bridge. We used FEM method to analysis the structure, which was modelled in ANSYS simplistically. It is mainly intended for verifying the bridge performance and the feasibility of the replacement. Fig. 6 shows the ANSYS finite element model of Dongmen Bridge.

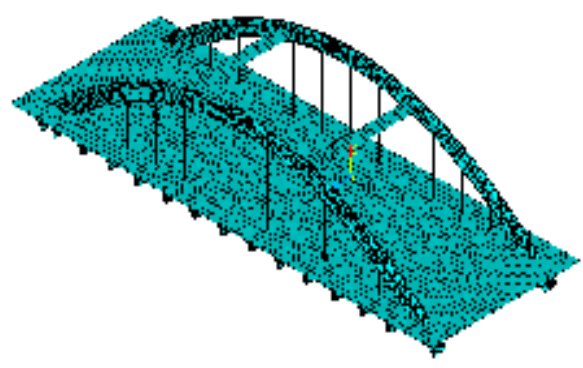

Figure. 6: Finite element model of Dongmen Bridge

Carbon fiber-reinforced polymer wires are produced by mixture of carbon fibers in a reasonable range. The properties of a CFRP wire can simply be calculated based on the rule of mixture, which includes modulus and strength. We used the fiber volume content in the range of $68-72 \%$.In contrast to steel, CFRP has low stiffness and much high strength. Properties of CFRP and steel are shown in Table 1. 
Table 1: Properties of CFRP and steel wires

\begin{tabular}{cccc} 
& CFRP & Steel & \\
\hline Tensile strength & 3,300 & 1090 & {$[\mathrm{MPa}]$} \\
Elastic modulus E & 165 & 195 & {$[\mathrm{GPa}]$} \\
Density & 1560 & 7850 & {$[\mathrm{Kg} / \mathrm{m} 3]$} \\
Fiber content & $68-72$ & $/$ & {$[\mathrm{Vol} \%]$} \\
\hline
\end{tabular}

After calculation, we have given the contrast analysis of the static and dynamic response of the whole bridge before and after the replacement. The vibrational frequency of the bridge changed little. The vibration mode shapes are almost as same as the initial bridge. It proved that the half-through arch bridge of CFRP hangers didn't lead to obvious changes on dynamic behavior. Table 2 shows the frequency of the bridges.

Table 2: The different vibrational frequency of the arch bridge

\begin{tabular}{ccc}
\hline \multirow{2}{*}{ SET } & \multicolumn{2}{c}{ Frequency /Time(s) } \\
& CFRP model & Steel model \\
\hline 1 & 0.7964 & 0.7821 \\
2 & 1.9904 & 1.9615 \\
3 & 2.8736 & 2.9072 \\
4 & 3.6270 & 3.6150 \\
5 & 4.0849 & 4.0286 \\
6 & 4.2789 & 4.2223 \\
7 & 4.3216 & 4.6824 \\
8 & 4.8845 & 4.8359 \\
9 & 5.3920 & 5.8876 \\
10 & 5.8221 & 6.0655 \\
\hline
\end{tabular}

We replaced the steel suspenders by CFRP based on the equal strength, which would lead to the decline of the stiffness. Correspondingly, the deflection of the beam attached by suspenders had to increase and the stress distribution of beams might change. We got the deflection of the bridge suffered the full load on the most unfavorable loading location. The distributed load was $42 \mathrm{KN} / \mathrm{m}$ and concentrated load was $1080 \mathrm{KN}$. The result shows that the stiffness of CFRP suspenders is lower and the relevant maximum deflection is just in a rational degree lager than the primal arch bridge with steel hangers. Fig.7 shows the maximum deflection at the bottom of the different suspenders. The results preliminarily prove the application of CFRP suspenders in arch bridges are available and has little effect on the characteristic of the bridge.

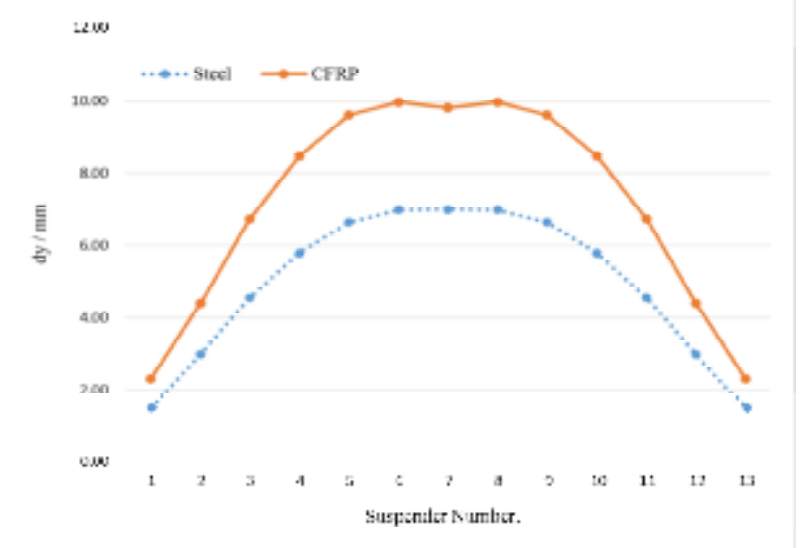

Figure.7: The maximum deflection at the bottom of the different suspenders

Concept and Application of Pin-loaded CFRP Strap System. A carbon fiber non-laminated pin-loaded strap, comprises a number of unidirectional reinforced layers, formed from a single, continuous tape of about $0.12 \mathrm{~mm}$ thickness .The concept which has been patented by Meier and Winistörfer (1998). The two pins could transfer the tensile load from the bridge deck through the 
strap to the arch rib. Compared with the original laminated pin-loaded strap, non-laminated strap has reduced the undesirable stress concentrations and the cost. The non-laminated strap element enables during loading the individual layers to move relative to each other, which allows an equalization of forces in the layers as the strap is tensioned. Control of the initial tensioning process reduces inter-laminar shear stress so that a more uniform strain distribution can be achieved in all layers. In Fig.8 the left one shows the conceptual design of laminated pin-loaded strap, and the right one is the non-laminated pin-loaded strap.

Suspenders made of pin-loaded CFRP straps can be fabricated with an automatic tape-laying of machine in the Carbo-Link Company or on site. As a flexible element it could easily be connected with a pin to the deck and another pin to the arch rib. The pin-loaded CFRP strap system has been successfully attached to the concrete foundation with pin-loading, which is applied for seismic retrofitting of a masonry post-tensioned wall. The results and the termination are shown in Fig.8.

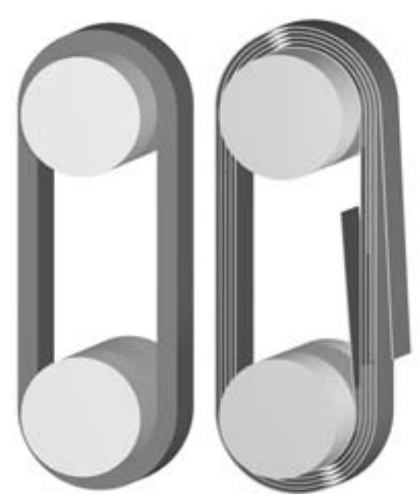

Figure8: Different pin-loaded strap elements
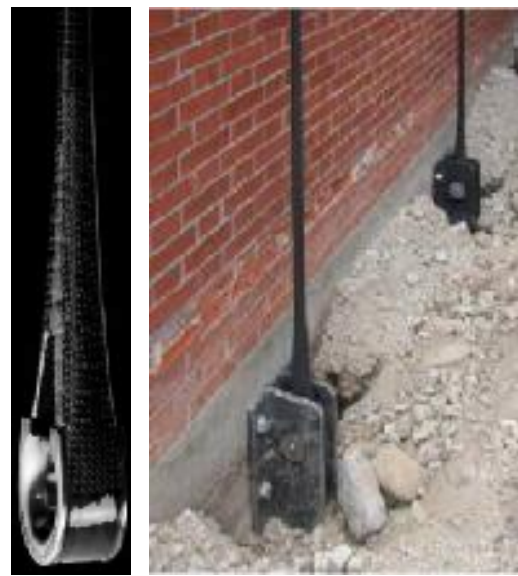

Figure9: Application of pin-loaded straps

\section{Conclusions}

Due to the excellent properties of carbon fibers, including light mass, very high specific strength and stiffness, outstanding fatigue behavior and corrosion resistance, CFRPs have always been one of the most advanced materials in technique. EMPA and BBR Ltd. in Switzerland have been researching CFRP as the cable materials for suspended structures since 1980. In China today, the interaction of the corrosion and fatigue is leading to many failures of suspenders in through and half-through arch bridges with overloading. Application of CFRP suspenders for through and half-through arch bridges has preliminarily been demonstrated the structural feasibility. And the above proposed pin-loaded CFRP strap system for bridge suspenders make it possible and easy for installation. The carbon fibers are wound in a racetrack manner around the pins. It became very difficult to make long-term life cycle predictions, as we have only to rely on the carbon fibers, the pins and not on grouts, polymers or adhesives. However based on the best knowledge available today we can assume that CFRP suspenders will outlast steel suspenders at least three times in the lifetime of service.

\section{Acknowledgements}

The research of this project is supported by the Chinese fundamental research funds for the central universities(granted no. 2013121028)

\section{References}

[1] Andrä W, and Zellner, W. 1969. Zugglieder aus Paralleldrahtbündeln und ihre Verankerung bei hoher Dauerschwellbelastung. Die Bautechnik, 46: Issues 8 and 9.

[2] Andrä, W, and Saul, R. 1974. Versuche mit Bündeln aus parallelen Drähten und Litzen. Die Bautechnik, 51: $289-298,332-340$ and $371-373$. 
[3] Brikenmaier, M, Brandestini, A, and Roš, M.R. 1952. Zur Entwicklung des vorgespannten Betons in der Schweiz. Schweizerische Bauzeitung, 70: 107-114.

[4] DIN. 2007. Leitfaden zum Anhang II-H, Hänger von Stabbogenbrücken des DIN- Fachberichtes 103(Ausgabe 2008).

[5] Evans, UR. 1982. An introduction to Metallic Corrosion.3rd Edition, Edward Arnolds (Publishers) Ltd. and American Society for Metals, 160. 